\title{
Growth of Nasal and Laryngeal Airways in Children: Implications in Breathing and Inhaled Aerosol Dynamics
}

\author{
Jinxiang Xi PhD, Xiuhua Si PhD, Yue Zhou PhD, JongWon Kim PhD, and Ariel Berlinski MD
}

\begin{abstract}
BACKGROUND: The human respiratory airway undergoes dramatic growth during infancy and childhood, which induces substantial variability in air flow pattern and particle deposition. However, deposition studies have typically focused on adult subjects, the results of which cannot be readily extrapolated to children. We developed models to quantify the growth of human nasallaryngeal airways at early ages, and to evaluate the impact of that growth on breathing resistance and aerosol deposition. METHODS: Four image-based nasal-laryngeal models were developed from 4 children, ages 10 days, 7 months, 3 years, and 5 years, and were compared to a nasallaryngeal model of a 53-year-old adult. The airway dimensions were quantified in terms of different parameters (volume, cross-section area, and hydraulic diameter) and of different anatomies (nose, pharynx, and larynx). Breathing resistance and aerosol deposition were computed using a highfidelity fluid-particle transport model, and were validated against the measurements made with the 3-dimensional models fabricated from the same airway computed tomography images. RESULTS: Significant differences in nasal morphology were observed among the 5 subjects, in both morphology and dimension. The turbinate region appeared to experience the most noticeable growth during the first 5 years of life. The nasal airway volume ratios of the 10-day, 7-month, 3-year, and 5 -year-old subjects were $6.4 \%, 18.8 \%, 24.2 \%$, and $40.3 \%$ that of the adult, respectively. Remarkable inter-group variability was observed in air flow, pressure drop, deposition fraction, and particle accumulation. The computational fluid dynamics predicted pressure drops and deposition fractions were in close agreement with in vitro measurements. CONCLUSIONS: Age effects are significant in both breathing resistance and micrometer particle deposition. The image/computational-fluid-dynamics coupled method provides an efficient and effective approach in understanding patient-specific air flows and particle deposition, which have important implications in pediatric inhalation drug delivery and respiratory disorder diagnosis. Key words: nasal morphology; childadult discrepancy; infants; breathing resistance; aerosol deposition; pediatric drug delivery. [Respir Care 2014;59(2):263-273. (C) 2014 Daedalus Enterprises]
\end{abstract}

\section{Introduction}

Considerable structural changes occur in human respiratory tracts during early ages, which lead to vast varia-

\footnotetext{
Drs Xi and Kim are affiliated with the Department of Mechanical and Biomedical Engineering, Central Michigan University, Mount Pleasant, Michigan. Dr Si is affiliated with the Department of Engineering, Calvin College, Grand Rapids, Michigan. Dr Zhou is affiliated with the Aerosol and Respiratory Dosimetry Program, Lovelace Respiratory Research Institute, Albuquerque, New Mexico. Dr Berlinski is affiliated with the Department of Pediatrics, University of Arkansas for Medical Science, Little Rock, Arkansas.
}

Dr Berlinski has disclosed relationships with Johnson \& Johnson, MPEX Pharmaceutical, Gilead, Philips, Genentech, Vertex, Abvie, and tions in breathing disorders that are specific to children. Compared to adults, infants and children are more suscep-

\footnotetext{
S\&T Technologies. None of their products are discussed in this paper. The other authors have disclosed no conflicts of interest.

Dr Xi presented a version of this paper at the OPEN FORUM of the AARC Congress 2012, held November 10-13, 2012, in New Orleans, Louisiana; for this research he was awarded the 2012 Monaghan-Trudell Fellowship for Aerosol Technique Development from the American Respiratory Care Foundation.
}

Correspondence: Jinxiang Xi PhD, Department of Mechanical and Biomedical Engineering, Central Michigan University, 1200 South Franklin Street, Mount Pleasant MI 48858. E-mail: xi1j@cmich.edu.

DOI: $10.4187 /$ respcare. 02568 
tible to respiratory distresses, due to their immature defense mechanism. Respiratory disease remains a leading cause of childhood morbidity in the United States and other developed countries, and is a leading cause of childhood deaths worldwide. Only by understanding the developmental respiratory system can we formulate effective protocols to treat an impaired physiology in pediatric patients.

A number of in vivo studies have been conducted to understand the development of respiratory morphology of early ages. Summaries of such studies can be found in recent reviews by Bassham et al ${ }^{1}$ and Ghuman et al. ${ }^{2}$ However, these studies mainly focused on the lower respiratory tract. Very few studies have considered the development of upper airway morphology. ${ }^{3}$ Clinical techniques for evaluating nasal pathology include visual analog scales, ${ }^{4}$ rhinostereometry, ${ }^{5}$ video-endoscopy, ${ }^{6}$ rhinomanometry, ${ }^{7}$ and acoustic rhinometry. ${ }^{8}$ A combination of the above techniques is usually employed in practice, based on the specific performance of each technique. ${ }^{9-12}$ Compared with clinical studies, computational fluid dynamics predictions have the advantage of providing detailed information on air flow and aerosol deposition, such as regional dosage, which are more relevant to health outcome than the average deposition. However, to our knowledge, very few computational fluid dynamics studies have been reported on the nasal morphology of children; one exception is $\mathrm{Xi}$ et al, ${ }^{13}$ who examined the upper airway structure and associated air flow dynamics in a 5-year-old child. The general neglect of child and infant airways in previous studies may largely be attributed to limited accessibility of pediatric medical images to computational fluid dynamics researchers, as well as the complexities involved in constructing physiologically realistic models of nasal passages.

The objective of this study was to characterize the growth of the upper airway with models created from images from 4 children, ages 10 days, 7 months, 3 years, and 5 years, using a coupled image/computational fluid dynamics approach. Our specific aims were: to develop anatomically accurate airway models of children, based on computed tomography and magnetic resonance imaging images; to quantify the airway dimensions; to numerically and experimentally determine the nasal-laryngeal resistance; and to numerically determine the inhaled particle deposition. The results of this study may improve our understanding of developmental respiratory morphology and its effects on children's health responses to environmental exposures and inhaled therapies.

\section{Methods}

\section{Nasal-Laryngeal Airway Models}

One example was used to illustrate the computer method to develop respiratory airway models based on computed tomography and magnetic resonance images. Figure 1

\section{QUICK LOOK}

\section{Current knowledge}

Aerosol deposition in the respiratory tract is affected by various well studied anatomic, equipment, and breathing-pattern variables, but most of the data have been from adults.

\section{What this paper contributes to our knowledge}

Anatomic differences associated with age affect total and regional aerosol deposition. There were important differences in airway anatomy, air-flow dynamics, and aerosol deposition between subjects ages 10 days, 7 months, 3 years, 5 years, and 53 years.

shows the procedures of translating a 2-dimensional magnetic resonance image (of a healthy 5 -year-old boy, weight $21 \mathrm{~kg}$, height $109 \mathrm{~cm})^{13}$ into a 3-dimensional model. The image tracings (see Fig. 1A) contained 128 slices, each $1.5 \mathrm{~mm}$ apart, that spanned from the nostrils to the upper trachea. The multi-slice tracings were segmented in medical image processing (Mimics, Materialise, Leuven, Belgium), based on the contrast between soft tissue and intranasal air, to isolate the nasal-laryngeal airway, which was further converted into a set of cross-sectional contours that define the airway. Based on these contours, an internal nasal surface geometry was constructed in engineeringdesign software (ANSYS Workbench, CAE Associates, Middlebury, Connecticut). The airway model can be either printed with 3-dimensional prototyping techniques for experimental purposes (see Fig. 1B) or discretized into a computational mesh for numerical analysis (see Fig. 1C). Due to the high complexity of the model geometry, an unstructured tetrahedral mesh was created with highresolution pentahedral elements in the near-wall region (see Fig. 1C). The respiratory geometry retained in this example extended from the nostrils to the upper trachea. In particular, anatomical details such as the epiglottal fold and laryngeal sinuses were retained (see Fig. 1A). The resulting model was intended to accurately represent the morphology of the upper airway, with only minor surface smoothing.

\section{Study Design}

Age effects on airway morphology, air flow, pressure drop, and inhaled particle deposition were assessed with nasal-laryngeal models created from computed tomography scans of 4 children (a 10-day-old female, a 7-monthold female, a 3-year-old female, and a 5-year-old male), seen at Arkansas Children Hospital, and one adult (a 53- 

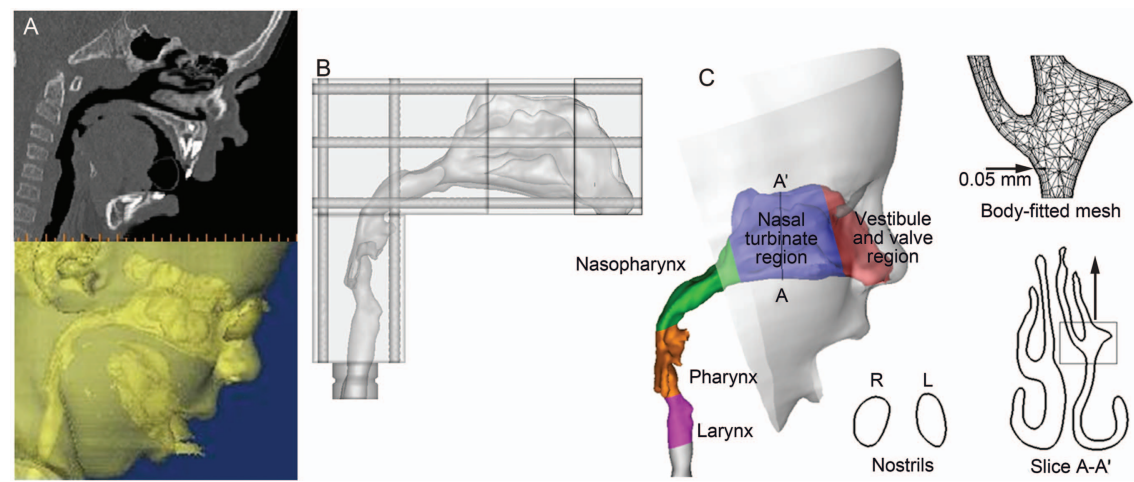

Fig. 1. Nasal-laryngeal airway model development. A: 3-dimensional rendering of computed tomography images of a 5-year-old male for (B) in vitro measurement and (C) numerical analysis. The airway was divided into regions: nasal vestibule and valve region, nasal turbinate, nasopharynx, pharynx, and larynx. The computational mesh is composed of approximately 1.8 million unstructured tetrahedral elements and a fine near-wall pentahedral grid.

Table 1. Respiratory Parameters Under Quiet Breathing Conditions

\begin{tabular}{|c|c|c|c|c|c|}
\hline & $\begin{array}{l}\text { 10-Day-Old } \\
\text { Female }\end{array}$ & $\begin{array}{l}\text { 7-Month-Old } \\
\text { Female }\end{array}$ & $\begin{array}{l}\text { 3-Year-Old } \\
\text { Female }\end{array}$ & $\begin{array}{l}\text { 5-Year-Old } \\
\text { Male }\end{array}$ & $\begin{array}{l}\text { 53-Year-Old } \\
\text { Male }\end{array}$ \\
\hline Breathing frequency, breaths/min & 44 & 25 & 22 & 21 & 12 \\
\hline Inspiratory-expiratory ratio & $1: 3$ & $1: 2$ & $1: 2$ & $1: 2$ & $1: 2$ \\
\hline Inhalation time, $\mathrm{s}$ & 0.34 & 0.8 & 0.9 & 0.95 & 1.67 \\
\hline Tidal volume, $\mathrm{mL}$ & 22 & 87 & 130 & 177 & 500 \\
\hline Percent of adult tidal volume & 4.4 & 17.4 & 26.0 & 35.4 & 100 \\
\hline Flow, L/min & 3.8 & 6.5 & 8.6 & 11.2 & 18.0 \\
\hline Inlet velocity, $\mathrm{m} / \mathrm{s}$ & 1.91 & 1.84 & 1.66 & 1.84 & 1.48 \\
\hline
\end{tabular}

(From data in References 14-16.)

year-old male). No health information was disclosed, and the use of the images was approved by the institutional review board of the University of Arkansas for Medical Science.

Steady inhalations were assumed for all simulations, with a wide spectrum of breathing conditions (1-45 L/ min). Comparison of the 5 models under equivalent physical activities (quiet breathing) were conducted, based on published respiratory parameters. ${ }^{14-16}$ Table 1 shows the literature-based, quiet-breathing respiratory parameters. Interestingly, the tidal volumes in all 5 models intimately correlated with the nasal-laryngeal airway volumes. As shown in Tables 1 and 2, relative to the adult model, the tidal volume ratios for the 10-day-old, 7-month-old, 3-yearold, and 5-year-old were, respectively, 4.4\%, 17.4\%, $26.0 \%$, and $35.4 \%$, while the airway volume ratios were respectively $6.4 \%, 18.8 \%, 24.2 \%$, and $40.3 \%$. Based on the nostril areas in Table 3 , the inlet velocities were similar between the 5 models under quiet breathing conditions. Initial particle velocities were assumed to be the same as the local fluid velocity. The airway surface was assumed to be smooth and rigid, with a no-slip (flow velocity at the wall $\left.\left[u_{\text {wall }}\right]=0\right)$ condition.

\section{Pressure Measurement}

We measured the pressure drops through the nasallaryngeal models with a manometer (Magnehelic Gage, Dwyer Instrument, Michigan City, Indiana). The model nostrils were open to room air, and a vacuum was connected to the manometer at the model outlet. We tested constant inhalation flows between 1 and $48 \mathrm{~L} / \mathrm{min}$, by adjusting the valve on the vacuum line. Flow was measured at the model outlet, with a flow meter (4140, TSI, Shoreview, Minnesota) positioned upstream of the flow valve.

\section{Numerical Method}

The low Reynolds number $k-\omega$ model was selected to simulate the air flow dynamics, based on its ability to accurately predict pressure drop, velocity profiles, and shear stress for multi-regime flows. ${ }^{13,17-19}$ The low Reynolds number $k$ - $\omega$ model applies to both laminar and turbulent flow regimes. Deposition fraction was calculated as the ratio of the amount of particles deposited on the airway 


\begin{tabular}{|c|c|c|c|c|c|}
\hline & \multicolumn{5}{|c|}{ Airway Volume $\left(\mathrm{cm}^{3}\right)$} \\
\hline & $\begin{array}{l}\text { 10-Day-Old } \\
\text { Female }\end{array}$ & $\begin{array}{l}\text { 7-Month-Old } \\
\text { Female }\end{array}$ & $\begin{array}{l}\text { 3-Year-Old } \\
\text { Female }\end{array}$ & $\begin{array}{l}\text { 5-Year-Old } \\
\text { Male }\end{array}$ & $\begin{array}{l}\text { 53-Year-Old } \\
\text { Male }\end{array}$ \\
\hline Vestibule and valve & 0.79 & 1.25 & 1.41 & 3.37 & 5.50 \\
\hline Turbinate region & 1.57 & 2.83 & 5.83 & 11.03 & 12.63 \\
\hline Nasopharynx & 0.48 & 1.74 & 1.07 & 3.95 & 16.33 \\
\hline Pharynx & 0.31 & 3.19 & 3.10 & 2.64 & 13.89 \\
\hline Larynx & 0.36 & 1.32 & 1.92 & 1.22 & 6.70 \\
\hline Total & 3.51 & 10.33 & 13.32 & 22.21 & 55.05 \\
\hline Percent of adult value & 6.4 & 18.8 & 24.2 & 40.3 & 100 \\
\hline
\end{tabular}

Table 3. Nasal Airway Surface Area

\begin{tabular}{|c|c|c|c|c|c|}
\hline & \multicolumn{5}{|c|}{ Airway Surface Area $\left(\mathrm{cm}^{2}\right)$} \\
\hline & $\begin{array}{l}\text { 10-Day-Old } \\
\text { Female }\end{array}$ & $\begin{array}{l}\text { 7-Month-Old } \\
\text { Female }\end{array}$ & $\begin{array}{l}\text { 3-Year-Old } \\
\text { Female }\end{array}$ & $\begin{array}{l}\text { 5-Year-Old } \\
\text { Male }\end{array}$ & $\begin{array}{l}\text { 53-Year-Old } \\
\text { Male }\end{array}$ \\
\hline Vestibule and valve & 7.45 & 9.75 & 18.97 & 23.74 & 35.58 \\
\hline Turbinate region & 21.09 & 35.63 & 54.71 & 107.34 & 112.59 \\
\hline Nasopharynx & 3.72 & 9.27 & 9.79 & 15.27 & 40.93 \\
\hline Pharynx & 2.96 & 13.71 & 13.92 & 14.59 & 45.10 \\
\hline Larynx & 2.87 & 8.37 & 9.46 & 7.20 & 12.81 \\
\hline Total & 38.09 & 76.73 & 106.85 & 168.14 & 256.01 \\
\hline Ratio, \% & 22.7 & 30.0 & 41.7 & 65.7 & 100 \\
\hline \multicolumn{6}{|l|}{ Inlets } \\
\hline Right nostril & 0.166 & 0.280 & 0.434 & 0.492 & 1.013 \\
\hline Left nostril & 0.166 & 0.315 & 0.431 & 0.437 & 1.013 \\
\hline Total & 0.332 & 0.595 & 0.865 & 0.929 & 2.026 \\
\hline Ratio, \% & 16.4 & 29.4 & 42.7 & 45.9 & 100 \\
\hline \multicolumn{6}{|l|}{ Outlets } \\
\hline Trachea & 0.178 & 0.506 & 0.671 & 0.832 & 1.487 \\
\hline Ratio, \% & 12.0 & 34.0 & 45.1 & 56.0 & 100 \\
\hline
\end{tabular}

surface to the amount of particles entering the nostrils. The transport and deposition of inhaled particles are simulated with a well tested discrete Lagrangian tracking model, enhanced with near-wall treatment. The inhaled particles were assumed to be dilute and to have no influence on the continuous phase (ie, one-way coupled particle motion). In our previous studies the Lagrangian tracking model, enhanced with user-defined routines, was shown to provide a close match to experimental deposition data in upper respiratory airways for both sub-micrometer ${ }^{18}$ and micrometer particles. ${ }^{17}$

To establish grid-independent results, convergence sensitivity analysis was conducted, following the methods of $\mathrm{Xi}$ et al. ${ }^{17}$ The final grids for reporting flow field consisted of 1.6-2.0 million cells, with a thin 5-layer pentahedral grid in the near-wall region and a cell height of $0.05 \mathrm{~mm}$ in the first layer (see Fig. 1C). The final number of particles tracked was 60,000; increasing the number of tracked particles did not alter the deposition fractions.

\section{Results}

\section{Airway Morphological and Dimensional Variations}

There were substantial morphological and dimensional differences between the 5 nasal-laryngeal airway models (Figs. 2 and 3). Younger subjects have smaller nostrils, a shorter turbinate region, a narrower nasopharynx, and a narrower pharynx-larynx. The nostril shape is more circular at birth, becomes more oval during infancy and childhood, and becomes wedge-shaped in adulthood. ${ }^{20}$ Of particular interest is the turbinate region, which seemed to be undeveloped in both the 10-day-old model and the 7-monthold model, and was much simpler in morphology than in our older children and adult models. The inferior meatus is missing in the 10-day-old. The inferior and middle meatuses apparently become both larger and more complex with age (see Fig. 2). 


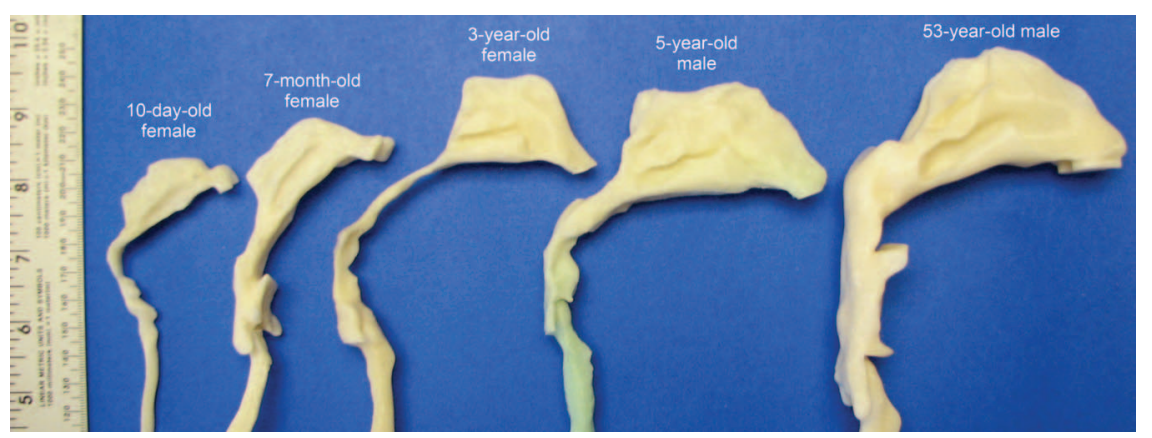

Fig. 2. Image-based nasal-laryngeal airway models of a 10-day-old female, a 7-month-old female, a 3-year-old female, a 5-year-old male, and a 53-year-old male.
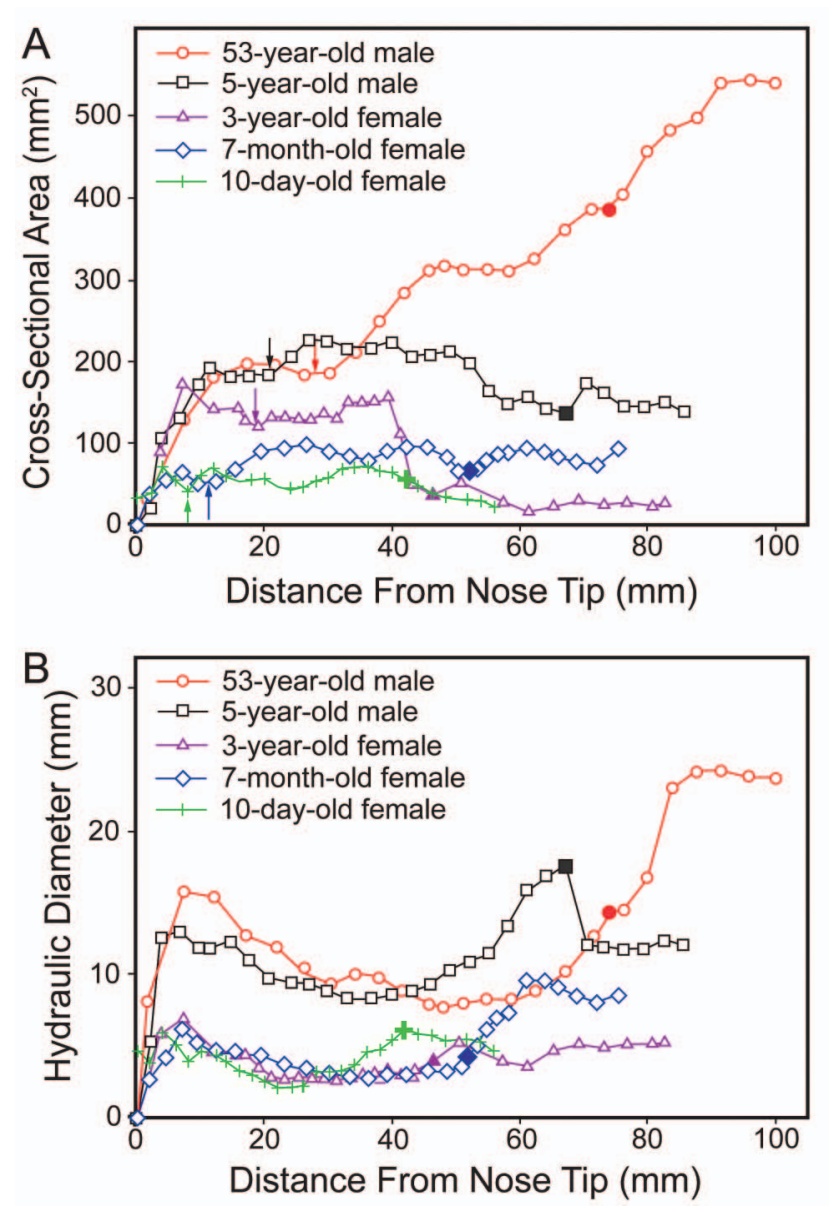

Fig. 3. Distance from nose tip versus cross-sectional area $(A)$ and hydraulic diameter $(B)$. In each curve the vertical arrow points to the nasal valve (ie, the minimum cross-sectional area), and the large, color-filled data point marks the beginning of the nasopharynx.

Figure 3 shows a quantitative comparison of the 5 models' airway dimensions, in terms of coronal cross-sectional area and perimeter, as a function of distance from the nose tip. Tables 2 and 3 compare the airway volumes and surface areas in the different anatomic sections. The nasal airway volumes of the 10-day-old, 7-month-old, 3-yearold, and 5-year-old were $6.4 \%, 18.8 \%, 24.2 \%$, and $40.3 \%$ that of the adult, respectively. The nasal airway surface areas were $22.7 \%, 30.0 \%, 41.7 \%$, and $65.7 \%$ that of the adult, respectively (see Table 3 ). There were 2 major disparities in the nasopharynx and nasal valve. First, compared to the adult, the children had a much smaller and narrower nasopharynx lumen. Figure 3A shows that the nasopharynx cross-sectional areas of the 10-day-old $\left(31 \mathrm{~mm}^{2}\right)$, the 7 -month-old $\left(78 \mathrm{~mm}^{2}\right)$, the 3-year-old $\left(29 \mathrm{~mm}^{2}\right)$, and the 5-year-old $\left(170 \mathrm{~mm}^{2}\right)$ were only $5.8 \%$, $15 \%, 5.4 \%$, and $32 \%$ that of the adult $\left(535 \mathrm{~mm}^{2}\right)$, respectively. The nasopharynx hydraulic diameters (hydraulic diameter $=(4 \times$ cross-sectional area $) /$ perimeter $)$ of the 10-day-old $(5.7 \mathrm{~mm}), 7$-month-old $(8.1 \mathrm{~mm}), 3$-year-old $(4.0 \mathrm{~mm})$, and 5-year-old $(12.2 \mathrm{~mm})$ were about $1 / 4,1 / 3$, $1 / 6$, and $1 / 2$ that of the adult $(24.0 \mathrm{~mm})$, respectively. Specifically, the 3-year-old seemed to have an abnormal nasopharynx that is narrower than the other 3 young subjects. The second major disparity is in the nostril-to-valve distances, which were much shorter in the 2 infants (8.0 $\mathrm{mm}$ in the 10-day-old, and $11.2 \mathrm{~mm}$ in the 7-monthold, see Fig. 3A) than in the 2 older children (both $\sim 20 \mathrm{~mm})$ and the adult $(27.2 \mathrm{~mm})$. The nasal valve crosssectional areas were likewise smaller in the 2 youngest subjects (ie, $\sim 42 \mathrm{~mm}^{2}$ in the 10-day-old, and $\sim 56 \mathrm{~mm}^{2}$ in the 7-month-old) than in the 2 older children and the adult (see Fig. 3A).

\section{Air Flow and Breathing Resistance}

Figure 4A shows the nasal air flows during quiet breathing, as stream lines within the right nasal passage. Highvelocity flows are observed in the middle portion of the nasal passage in all the models. The main flow changes direction dramatically from the nostrils to the nasopharynx, forming a nearly $180^{\circ}$ curvature. However, this curvature is less severe in the 7-month-old model than in the other 3 models, presumably resulting from a more backtilted head position during image acquisition. The air speed 
A Stream Lines
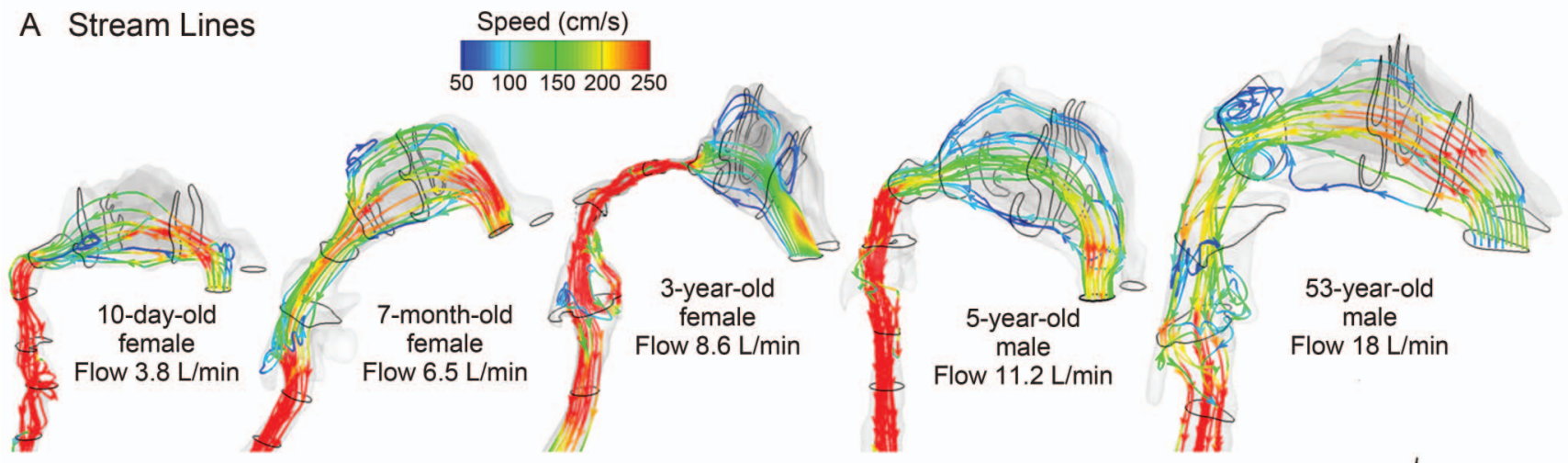

\section{B Particle locations at time points}

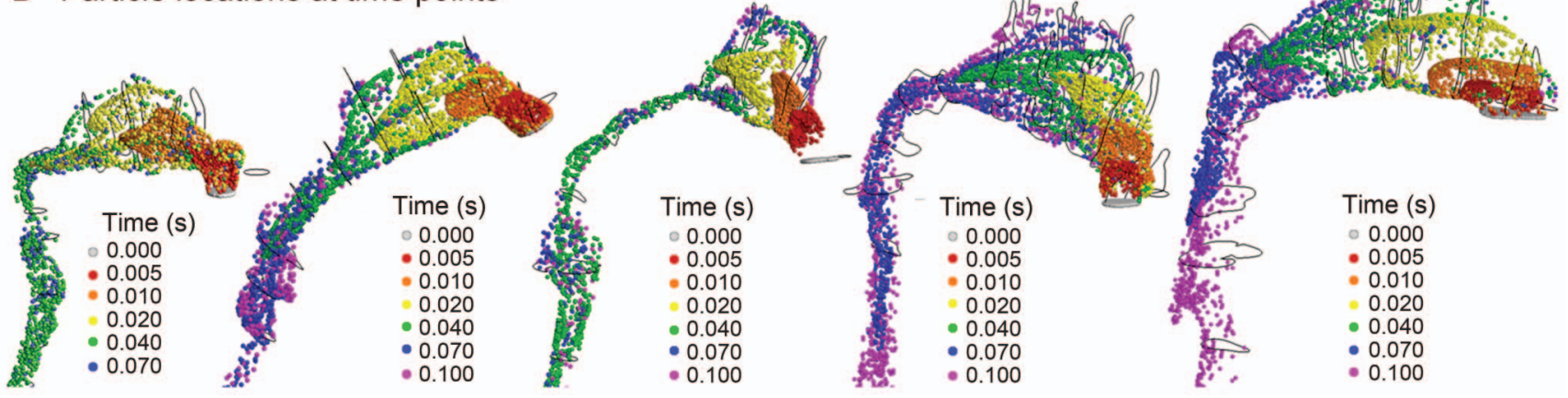

Fig. 4. A: Inhaled-gas stream lines inside the right nasal-laryngeal airways during quiet breathing. B: Flow pattern visualized with mass-less fluid aerosol particles at various time points.

was higher in the nasopharynx of the 3-year-old, due to the severe nasopharynx constriction. No recirculation zone was observed in the nasopharynx of the 3 young subjects, due to a much smaller airway diameter in this region, which differs from the adult nasopharynx, in which flow recirculation is obvious (see Fig. 4A).

Air flow dynamics within the nasal passages are further visualized in Figure 4B as snapshots of particle locations at selected instants. Two thousand $1.0-\mu \mathrm{m}$ particles were released at the right nostril, and particle positions were recorded at designated time points. Due to their small inertia, $1.0-\mu \mathrm{m}$ particles are assumed to closely follow the air flow. Faster transport and deeper penetration of aerosols are apparent in the medial passages, while slowmoving particles are found near the airway walls. Because of the dramatic airway bend from the nostrils to the nasopharynx, a high-concentration of particles constantly adjust their directions, following the mean stream-line curvature of inhaled air flow. The seemingly random particle distributions in the pharynx indicate enhanced turbulent mixing in this region. Due to the smaller nasopharynxlarynx regions in children, particles are transported faster and reach the glottal aperture faster than in the adult. This difference was more pronounced in the 3-year-old model, which had an abnormally narrow naso- and velopharynx.
The comparison of measured and computational-fluiddynamics-predicted pressure drop $(\Delta \mathrm{P})$ for the 5 models is shown in Figure 5, for the flow range 1-48 L/min. All the models are in close agreement. The in vitro experiments and the computational-fluid-dynamics-predictions were conducted in the same airway geometry models, so direct comparison is possible. In general, the pressure drop (ie, breathing resistance) decreased as age increased (see Fig. 5). For a given flow, the infant and children models had much higher breathing resistance than the adult model. However, it is also not surprising that the 3-yearold model had a much higher pressure drop than the 7-month-old model, considering the abnormally constricted nasopharynx in the 3-year-old model and the less severe airway curvature in the 7-month-old model. The flow-pressure relationships can be expressed as a power function $\left(\Delta \mathrm{P}=\mathrm{a} \cdot \mathrm{Q}^{\mathrm{b}}\right)$, which can be plotted as straight lines on a $\log -\log$ scale with a slope of $b$, as shown in the logarithmic graph in Figure 5. The best-fitted coefficients $a$ and $b$ for the different model ages are listed in Table 4.

\section{Particle Deposition}

Particle deposition in the nasal-laryngeal airway of the 5-year-old is displayed in Figure 6A, for the particle range 

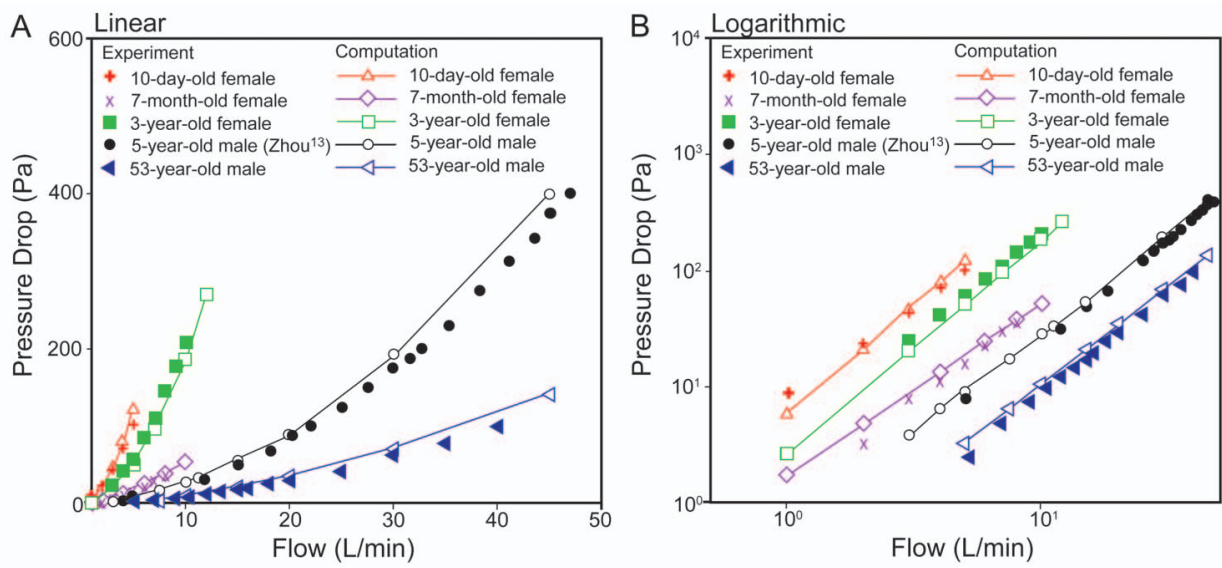

Fig. 5. Linear and logarithmic models of flow versus pressure inside 5 nasal-laryngeal airway models.

Table 4. Flow-Pressure Correlation Coefficients

\begin{tabular}{llcc}
\hline \hline \multirow{2}{*}{ Model } & \multicolumn{1}{c}{ Imaging Method } & \multicolumn{2}{c}{$\begin{array}{c}\text { Correlation } \\
\text { Coefficient }\end{array}$} \\
\cline { 3 - 4 } & & Slope a & Slope b \\
\hline 10-day-old female & Computed tomography & 5.86 & 1.89 \\
7-month-old female & Computed tomography & 1.77 & 1.48 \\
3-year-old female & Computed tomography & 2.71 & 1.84 \\
5-year-old male & Magnetic resonance imaging & 0.58 & 1.70 \\
53-year-old male & Magnetic resonance imaging & 0.21 & 1.71 \\
\hline
\end{tabular}

$2.5-40 \mu \mathrm{m}$, at a flow of $10 \mathrm{~L} / \mathrm{min}$. There was highly heterogeneous particle distribution for all particle sizes considered, and the variation of deposition location with particle size is clearly shown. Particles $\geq 40 \mu \mathrm{m}$ are mostly filtered out in the nasal vestibule (gray points in Fig. 6A). Particles around $20 \mu \mathrm{m}$ deposit mainly in the superior and middle nasal passages, due to their higher inertia. Particles around $10 \mu \mathrm{m}$ tend to deposit further downward, mainly in the middle passage. Particles around $2.5 \mu \mathrm{m}$, which can closely follow the mainstream air flow, deposit mainly in the middle and lower passages.

The deposition fraction as a function of particle aerodynamic diameter is shown in Figure 6B, in comparison with experimental data from Zhou et al. ${ }^{13,21}$ The inhalation flows considered were 10 and $20 \mathrm{~L} / \mathrm{min}$, and the particle size range was $0.5-32 \mu \mathrm{m}$. The in vitro experiments of Zhou et $\mathrm{al}^{21}$ and the current computational-fluiddynamics predictions are based on the same airway geometry model. Again, there is a close match between the predicted and the measured deposition, with slight underestimation by computational fluid dynamics, compared to the experimental measurements at $20 \mathrm{~L} / \mathrm{min}$. For both flows, particles larger than $10 \mu \mathrm{m}$ are mostly filtered out in this pediatric nasal-laryngeal airway (ie, the cut size being $10 \mu \mathrm{m})$. For particles smaller than $10 \mu \mathrm{m}$ the deposition rate exhibits a high sensitivity to the aerosol size and flow, which increases quickly as the aerosol size or flow increases.

The age-related effects on nasal deposition among the 5 models are shown in Figure 7 under equivalent physical activity (ie, sedentary) conditions. The particle sizes considered are $2.5 \mu \mathrm{m}$ and $10 \mu \mathrm{m}$. Large variability is observed among the 5 models, both in deposition pattern (see Fig. 7A) and regional deposition fractions (see Fig. 7B). For small particles $(2.5 \mu \mathrm{m})$, the deposition fraction is very low in the 3 regions (ie, anterior, middle, and posterior). One exception is in the 3 -year-old model, in which elevated deposition is presumably attributable to the more constricted nasopharynx. For large particles $(10 \mu \mathrm{m})$ nasal deposition increases by approximately one order of magnitude. Again, the highest deposition was in the 3-year-old model. Considering regional deposition, the allocation of deposition fractions in the 3 regions differs for $2.5 \mu \mathrm{m}$ and $10 \mu \mathrm{m}$ particles in each model. For $2.5 \mu \mathrm{m}$ particles the anterior region (nasal vestibule and valve) generally receives more particles than the others. In contrast, the middle (turbinate) region receives more deposition for $10 \mu \mathrm{m}$ particles (see Fig. 7B). A high deposition of $10 \mu \mathrm{m}$ particles is found in the anterior region in the adult model, but not in the infant and child models. If considering the anterior and middle regions together (nasal passage), the adult model filters more $10 \mu \mathrm{m}$ particles than the children models. This may result from the higher complexity of the adult nasal passages.

\section{Discussion}

There is enormous physiological growth during infancy and childhood. Substantial differences were noted in the nose-throat morphology among the 5 subjects of different ages. These differences manifest themselves not only in airway dimension but also in airway morphology. For example, the nasal-laryngeal airway volumes of the 10-day- 

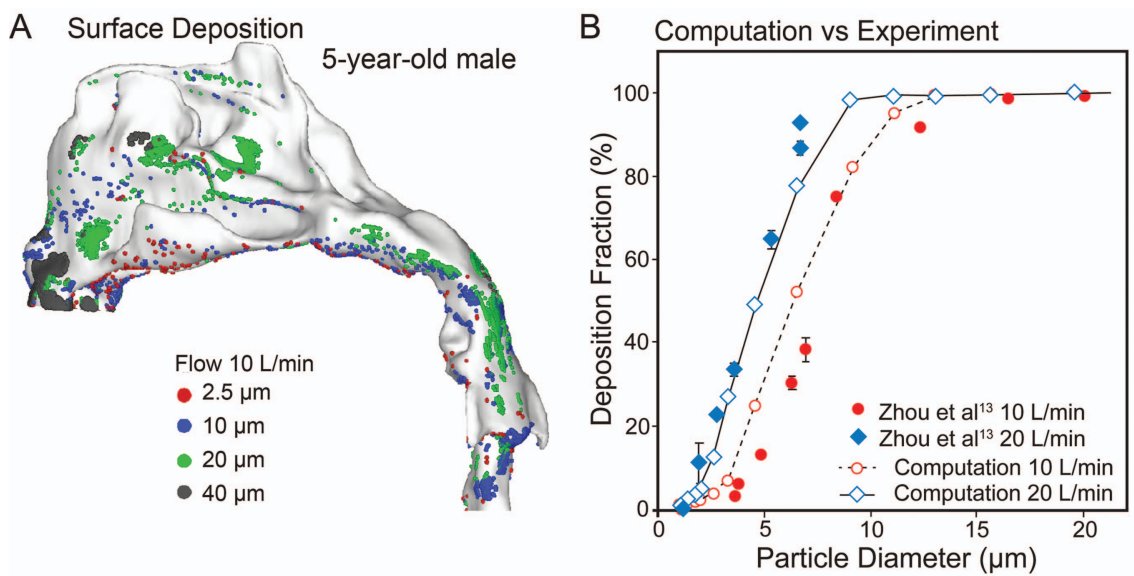

Fig. 6. A: Particle deposition in the nasal-laryngeal airway of the 5-year-old model. There was heterogeneous deposition distribution on the airway surface. B: There was a close match between the measured and computed deposition fractions for both $10 \mathrm{~L} / \mathrm{min}$ and $20 \mathrm{~L} / \mathrm{min}$.
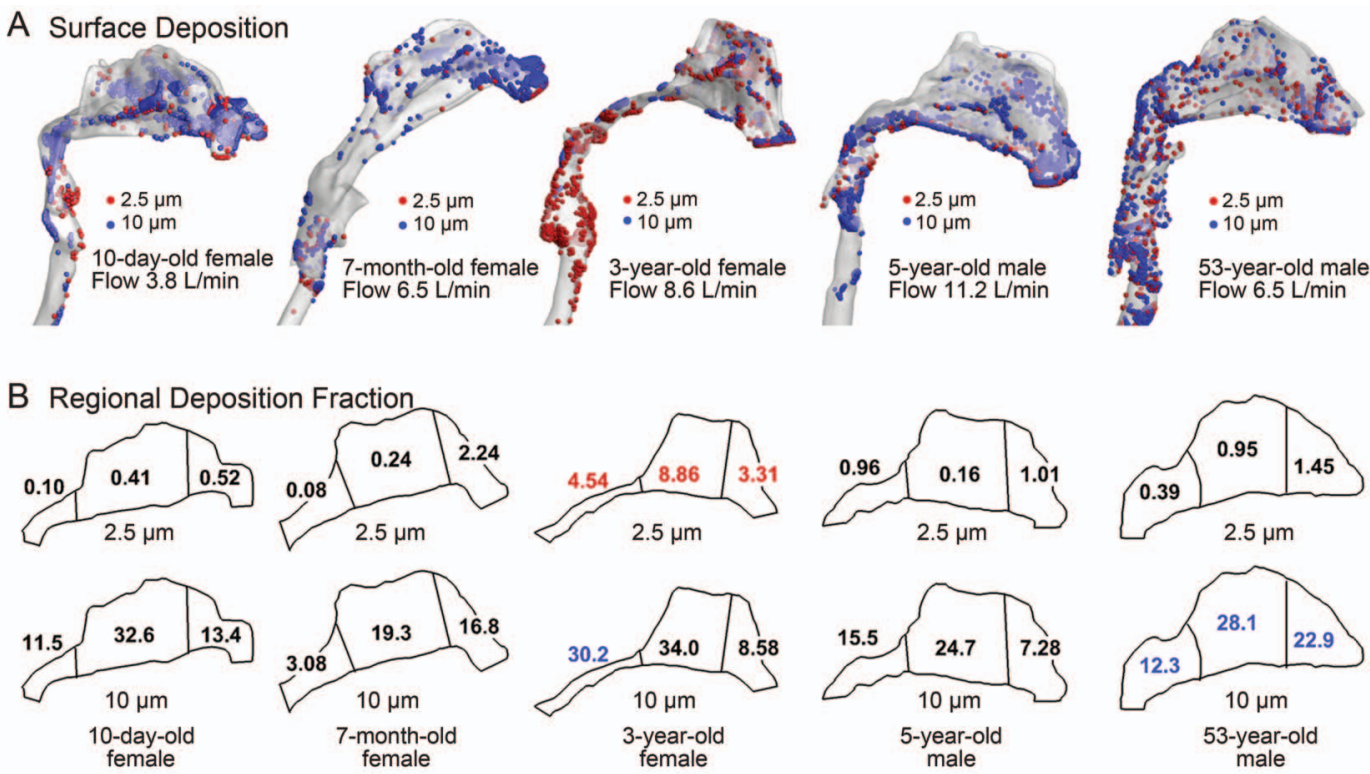

Fig. 7. Surface deposition (A) and sub-region deposition (B) fractions in 5 nasal-laryngeal airway models during quiet breathing. The model surfaces are $50 \%$ translucent.

old, 7-month-old, 3-year-old, and 5-year-old were $6.4 \%$, $18.8 \%, 24.2 \%$, and $40.3 \%$ that of the 53 -year-old, respectively. The 4 young subjects have smaller nostrils, a shorter turbinate region, and a narrower nasopharynx. The results of this study suggest that the nasal valve and vestibule region mature between the ages 3 and 5. This is supported by the much shorter nostril-valve distance and much smaller cross-sectional area of the nasal valve in the 2 infants, compared to the 2 older children, as well as the proximity of the these 2 parameters between the adult and the 2 older children (see Fig. 3A). Specifically, the nostril-valve dis- tances are 8.0-11.2 $\mathrm{mm}$ for the 2 infants, versus 19.0 $20.8 \mathrm{~mm}$ for the 2 children and $27.2 \mathrm{~mm}$ for the adult. The nasal valve areas are $42-56 \mathrm{~mm}^{2}$ for the infants, versus $120-180 \mathrm{~mm}^{2}$ for the children and adult.

Our models suggest that the turbinate region experiences fast growth from birth to the age of 5, as indicated by the remarkable volume increase of this region: $1.57 \mathrm{~cm}^{3}$ in the 10-day-old, $2.83 \mathrm{~cm}^{3}$ in the 7-month-old, $5.83 \mathrm{~cm}^{3}$ in the 3 -year-old, $11.03 \mathrm{~cm}^{3}$ in the 5 -year-old, and $12.63 \mathrm{~cm}^{3}$ in the 53-year-old (see Table 2). However, a lack of similarity in shape between the 5-year-old and the adult may 
still indicate an undeveloped turbinate region at the age of 5. It is apparent that the nasopharynx grows the least, compared to other parts of the respiratory anatomy, during the first 5 years of life: the nasopharynx volume was $0.48 \mathrm{~cm}^{3}$ in the 10-day-old, $1.74 \mathrm{~cm}^{3}$ in the 7-month-old, $1.07 \mathrm{~cm}^{3}$ in the 3-year-old, $3.95 \mathrm{~cm}^{3}$ in the 5-year-old, and $16.33 \mathrm{~cm}^{3}$ in the 53-year-old (see Table 2). Further studies on more age groups are necessary to quantify the developmental respiratory morphology and its effects on breathing and aerosol filtration.

A power function $\left(\Delta \mathrm{P}=\mathrm{a} \cdot \mathrm{Q}^{\mathrm{b}}\right)$ has been used to correlate the breathing frequency and airway pressure drop in previous studies. ${ }^{22,23}$ The flow-pressure relation shows high sensitivity to age in this study, as indicated by the large variation of "a" for different age groups (5.86-0.21 from 10-D-F to 53-Y-M, Table 4). For an equivalent physical activity, the inhalation rates are different for the different ages, due to their particular respiratory variables such as frequency, inspiratory-expiratory ratio, and tidal volume. Based on the selected flows $(3.8 \mathrm{~L} / \mathrm{min}$ for the 10-day-old, $6.5 \mathrm{~L} / \mathrm{min}$ for the 7-month-old, $9.5 \mathrm{~L} / \mathrm{min}$ for the 3-year-old, $11.2 \mathrm{~L} / \mathrm{min}$ for the 5-year-old, and $18 \mathrm{~L} /$ min for the 53-year-old), the nasal breathing resistance is highest for the 10-day-old model, and decreases with age in normal subjects. Furthermore, this decrease appears most dramatic in the first year (10-day-old vs 7-month-old model herein), and the rate of decrease becomes gradually smaller beyond this age. Interestingly, a similar observation in breathing frequencies was reported by Fleming et al, ${ }^{15}$ who studied 3,381 children and found a constant decline in breathing frequency from birth to adolescence, with the steepest fall in infants under 2 years of age.

The flow-pressure relationship also shows high sensitivity to airway abnormalities, as suggested by the abrupt increase in magnitude of slope $b$ in the 3-year-old, who had a more constricted nasopharynx (see Table 4). In this case, the subject may expect increased respiratory effort when awake and obstructive sleep apnea symptoms during sleep. The results of this study indicate that computational modeling could be a supplemental tool to study breathingrelated disorders. By providing detailed air flow information that is not readily measured by conventional diagnosis techniques, ${ }^{24}$ additional clues may be unveiled that are clinically relevant to breathing disorders such as snoring and sleep apnea.

Deposition patterns of inhaled aerosols are not uniform in human upper airways; there is heterogeneous deposition in the different anatomic regions. ${ }^{17,25,26}$ The regional deposition allocations we observed varied substantially among the different age models. Considering that tissues receiving higher depositions of toxicants are more vulnerable to injury, such results might help to elucidate the diverse etiology and symptoms of respiratory disorders in different subjects or age groups. The deposition in the 3 regions considered (vestibule-valve, turbinate, and nasopharynx) was remarkably different among the 5 models, indicating a different level of risks upon the region of interest, even when exposed to the same environment. The higher turbinate deposition in the 3-year-old model may suggest a higher chance of nasal inflammation and exacerbate existing symptoms of difficult breathing. On the other hand, outcomes from inhalation therapies require drugs to be delivered to the targeted tissues at a sufficient dose. The heterogeneity in regional deposition among the different ages implies that existing adult deposition results might not guarantee an accurate dosimetry planning for infants and children.

\section{Limitations}

Limitations of this study include the assumptions of steady flow, quiet breathing only, rigid airway walls, idealized particles, and a limited number of samples per age. Other studies have highlighted the physical importance of tidal breathing, ${ }^{27}$ effects of physical activities, ${ }^{27}$ airway wall motion, ${ }^{28}$ and nasal valve collapse. ${ }^{29}$ Environmental aerosols are mostly non-spherical, ${ }^{30}$ interacting among themselves, ${ }^{31}$ and undergo size changes due to hygroscopic effects ${ }^{32}$ or coagulation. ${ }^{33}$ Moreover, each model in this study was based on images of one subject, which does not account for inter-subject variability which can be substantial. ${ }^{34,35}$ Another limitation is the typical supine position of the subjects during data acquisition, which is different from sedentary breathing. Images acquired at the end of the inhalation may not reflect variations in airway geometry during a full breathing cycle. Therefore, future studies are needed that should be oriented toward improving physical realism and including a broader population group. Our knowledge of nasal deposition is currently lacking in subpopulations such as pediatrics, geriatrics, and patients with respiratory diseases. Due to physiological development, aging, or disease states, the airway morphology can be remarkably different from that of a healthy adult. Concentrating on these specific subpopulations will help to clarify inter-group and inter-individual variability and will allow for the design of more efficient pharmaceutical formulations and drug delivery protocols for different age groups. In addition, further methodology developments and deposition measurements are required to provide robust estimates of airway depositions of either airborne contaminants or inhaled pharmacologic particles.

\section{Conclusions}

Substantial variability exists in airway morphology, air flow dynamics, and aerosol deposition among subjects of different ages. Specific observations include: 


\section{Growth of Nasal and Laryngeal Airways in Children}

- The nasal airway volumes of the 10-day-old, 7-monthold, 3-year-old, and 5-year-old were 6.4\%, 18.8\%, 24.2\%, and $40.3 \%$ that of the 53-year-old adult, respectively, and the nasal airway surface areas were $22.7 \%, 30.0 \%$, $41.7 \%$, and $65.7 \%$ that of the adult, respectively.

- The airway pressure drop is sensitive to age and airway abnormalities. Flow-pressure correlations have been proposed for different age groups based on a wide range of breathing conditions.

- Age effects are large in both total and regional aerosol deposition, and should be considered in future environmental health assessment and inhaled drug delivery.

- Satisfactory agreements between computational-fluiddynamics predictions and in vitro experiments were obtained in pressure drop and particle deposition, indicating that the image/computational-fluid-dynamics coupled method is a practical tool in diagnosing respiratory disorders and developing effective inhalation devices.

\section{REFERENCES}

1. Bassham BS, Kane I, MacKeil-White K, Fischer J, Arnold D, Whatley V, et al. Difficult airways, difficult physiology and difficult technology: respiratory treatment of the special needs child. Clin Pediatr Emerg Med 2012;13(2):81-90.

2. Ghuman AK, Newth CJL, Khemani RG. Respiratory support in children. Paediatr Child Health 2011;21(4):163-169.

3. Brodsky L. Chapter 35 - Structure and Development of the Upper Respiratory System in Infants and Children. Pediatric Critical Care, 4th edition. Saint Louis: Mosby; 2011;485-489.

4. Ernstgard L, Bottai M. Visual analogue scales: how can we interpret them in experimental studies of irritation in the eyes, nose, throat and airways? J Appl Toxicol 2012;32(10):777-782.

5. Ellegard E. Practical aspects on rhinostereometry. Rhinology 2002; 40(3):115-117.

6. Keck T, Leiacker R, Kuhnemann S, Lindemann J, Rozsasi A, Wantia N. Video-endoscopy and digital image analysis of the nasal valve area. Eur Arch Otorhinolaryngol 2006;263(7):675-679.

7. Demirbas D, Cingi C, Cakli H, Kaya E. Use of rhinomanometry in common rhinologic disorders. Exp Rev Med Dev 2011;8(6): 769-777.

8. Wheeler SM, Corey JP. Evaluation of upper airway obstruction - an ENT perspective. Pulm Pharmacol Ther 2008;21(3):433-441.

9. Kesavanathan J, Swift DL, Fitzgerald TK, Permutt T, Bascom R. Evaluation of acoustic rhinometry and posterior rhinomanometry as tools for inhalation challenge studies. J Toxicol Environ Health 1996; 48(3):295-307.

10. Pirila T, Nuutinen J. Acoustic rhinometry, rhinomanometry and the amount of nasal secretion in the clinical monitoring of the nasal provocation test. Clin Exp Allergy 1998;28(4):468-477.

11. Porter MJ, Williamson IG, Kerridge DH, Maw AR. A comparison of the sensitivity of manometric rhinometry, acoustic rhinometry, rhinomanometry and nasal peak flow to detect the decongestant effect of xylometazoline. Clin Otolaryngol 1996;21(3):218-221.

12. Pirila T, Tikanto J. Acoustic rhinometry and rhinomanometry in the preoperative screening of septal surgery patients. Am J Rhinol Allergy 2009;23(6):605-609.

13. Xi J, Si X, Kim JW, Berlinski A. Simulation of airflow and aerosol deposition in the nasal cavity of a 5-year-old child. J Aerosol Sci 2011;42(3):156-173.

14. Gagliardi L, Rusconi F, Castagneto M, Porta GLN, Razon S, Pellegatta A. Respiratory rate and body mass in the first three years of life. Arch Dis Child 1997;76(2):151-154.

15. Fleming S, Thompson M, Stevens R, Heneghan C, Plüddemann A, Maconochie I, et al. Normal ranges of heart rate and respiratory rate in children from birth to 18 years of age: a systematic review of observational studies. Lancet 2011;377(9770):1011-1018.

16. Rusconi F, Castagneto M, Porta N, Gagliardi L, Leo G, Pellegatta A, et al. Reference values for respiratory rate in the first 3 years of life. Pediatrics 1994;94(3):350-355.

17. Xi J, Longest PW. Transport and deposition of micro-aerosols in realistic and simplified models of the oral airway. Ann Biomed Eng 2007;35(4):560-581.

18. Xi J, Longest PW. Effects of oral airway geometry characteristics on the diffusional deposition of inhaled nanoparticles. J Biomech Eng 2008;130:011008.

19. Xi J, Longest PW, Martonen TB. Effects of the laryngeal jet on nano- and microparticle transport and deposition in an approximate model of the upper tracheobronchial airways. J Appl Physiol 2008; 104:1761-1777.

20. Xi J, Longest PW. Numerical predictions of submicrometer aerosol deposition in the nasal cavity using a novel drift flux approach. Int J Heat Mass Transfer 2008;51(23-24):5562-5577.

21. Zhou Y, Xi J, Simpson J, Irshad H, Cheng YS. Aerosol deposition in a nasopharyngolaryngeal replica of a 5-year-old child. Aerosol Sci Technol 2013;47:275-282.

22. Garlick SR, Gehring JM, Wheatley JR, Amis TC. Nasal airflow resistance and the flow resistive work of nasal breathing during exercise: effects of a nasal dilator strip. Am J Respir Crit Care Med 1999;159(3):A417-A417

23. Wheatley JR, Amis TC, Engel LA. Nasal and oral airway pressureflow relationships. J Appl Physiol 1991;71(6):2317-2324.

24. Flemons WW, Buysse D, Redline S, Pack A, Strohl K, Wheatley J, et al. Sleep-related breathing disorders in adults: recommendations for syndrome definition and measurement techniques in clinical research. Sleep 1999;22(5):667-689.

25. Si X, Xi J, Kim JW, Zhou Y, Zhong H. Modeling of release position and ventilation effects on olfactory aerosol drug delivery. Respir Physiol Neurobiol 2013;186:22-32.

26. Xi J, Longest PW. Evaluation of a drift flux model for simulating submicrometer aerosol dynamics in human upper tracheobronchial airways. Annals of Biomed Eng 2008;36(10):1714-1734

27. Haussermann S, Bailey AG, Bailey MR, Etherington G, Youngman $M$. The influence of breathing patterns on particle deposition in a nasal replicate cast. J Aerosol Sci 2002;33(6):923-933.

28. Fodil R, Brugel-Ribere L, Croce C, Sbirlea-Apiou G, Larger C, Papon JF, et al. Inspiratory flow in the nose: a model coupling flow and vasoerectile tissue distensibility. J Appl Physiol 2005;98(1): 288-295.

29. Bridger GP, Proctor DF. Maximum nasal inspiratory flow and nasal resistance. Ann Otol Rhinol Laryngol 1970;79(3):481-488.

30. Tian L, Ahmadi G, Wang ZC, Hopke PK. Transport and deposition of ellipsoidal fibers in low Reynolds number flows. J Aerosol Sci 2012;45:1-18

31. Nasr H, Ahmadi G, McLaughlin JB. A DNS study of effects of particle-particle collisions and two-way coupling on particle deposition and phasic fluctuations. J Fluid Mech 2009;640: 507-536. 


\section{Growth of Nasal and Laryngeal Airways in Children}

32. Longest PW, Xi JX. Condensational growth may contribute to the enhanced deposition of cigarette smoke particles in the upper respiratory tract. Aerosol Sci Technol 2008;42(8):579-602.

33. Okuyama K, Kousaka Y, Hayashi K. Change in size distribution of ultrafine aerosol particles undergoing Brownian coagulation. J Colloid Interface Sci 1984;101(1):98-109.
34. Storey-Bishoff J, Noga M, Finlay WH. Deposition of micrometersized aerosol particles in infant nasal airway replicas. J Aerosol Sci 2008;39(12):1055-1065.

35. Garcia GJM, Tewksbury EW, Wong BA, Kimbell JS. Interindividual variability in nasal filtration as a function of nasal cavity geometry. J Aerosol Med Pulm Drug Deliv 2009;22(2):139-155. 